\title{
Parent-child communication about sexual and reproductive health: evidence from the Brong Ahafo region, Ghana
}

\author{
Abubakar A Manu ${ }^{1 *}$, Chuks Jonathan Mba², Gloria Quansah Asare ${ }^{3}$, Kwasi Odoi-Agyarko ${ }^{4}$ \\ and Rexford Kofi Oduro Asante ${ }^{5}$
}

\begin{abstract}
Background: Young people aged 10-24 years represent one-third of the Ghanaian population. Many are sexually active and are at considerable risk of negative health outcomes due to inadequate sexual and reproductive health knowledge. Although growing international evidence suggests that parent-child sexual communication has positive influence on young people's sexual behaviours, this subject has been poorly studied among Ghanaian families. This study explored the extent and patterns of parent-child sexual communication, and the topics commonly discussed by parents.
\end{abstract}

Methods: A cross-sectional design was used to sample 790 parent-child dyads through a two-stage cluster sampling technique with probability proportional to size. Interviewer-administered questionnaire method was used to gather quantitative data on parent-child communication about sex. Twenty sexual topics were investigated to describe the patterns and frequency of communication. The Pearson's chi-square and z-test for two-sample proportions were used to assess sexual communication differences between parents and young people. Qualitative data were used to flesh-out relevant issues which standard questionnaire could not cover satisfactorily.

Results: About $82.3 \%$ of parents had at some point in time discussed sexual and reproductive health issues with their children; nonetheless, the discussions centered on a few topics. Whereas child-report indicated that $78.8 \%$ of mothers had discussed sexual communication with their children, $53.5 \%$ of fathers had done so. Parental discussions on the 20 sexual topics ranged from 5.2\%-73.6\%. Conversely, young people's report indicates that mother-discussed topics ranged between 1.9\%-69.5\%, while father-discussed topics ranged from $0.4 \%$ to $46.0 \%$. Sexual abstinence was the most frequently discussed topic (73.6\%), followed by menstruation 63.3\% and HIV/AIDS 61.5\%; while condom (5.2\%) and other contraceptive use (9.3\%) were hardly discussed. The most common trigger of communication cited by parent-child dyads was parent's own initiation $(59.1 \%$ vs. $62.6 \% p=0.22)$.

Conclusions: Parents in the Brong Ahafo region of Ghana do talk to children about sex, but their conversations cover limited topics. While abstinence is the most widely discussed sexual topic, condoms and contraception were rarely discussed. Sex educational programmes ought to encourage parents to expand sexual communication to cover more topics.

Keywords: Parent-child sexual communication, Young people, Sexual topics, Reproductive health, Ghana

\footnotetext{
* Correspondence: abumanu@yahoo.com

'Department of Population, Family, \& Reproductive Health, School of Public

Health, College of Health Sciences, University of Ghana, P.O. Box LG 13,

Accra, Ghana

Full list of author information is available at the end of the article
}

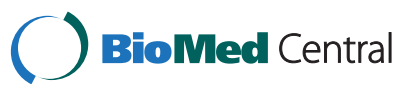

(c) 2015 Manu et al.; licensee BioMed Central. This is an Open Access article distributed under the terms of the Creative Commons Attribution License (http://creativecommons.org/licenses/by/4.0), which permits unrestricted use, distribution, and reproduction in any medium, provided the original work is properly credited. The Creative Commons Public Domain Dedication waiver (http://creativecommons.org/publicdomain/zero/1.0/) applies to the data made available in this article, unless otherwise stated. 


\section{Background}

Young people aged 10-24 years face multiple challenges during their transition to adulthood. Even though the transition from childhood to adulthood lasts about 15 years, many young people could acquire significant preventable health problems before reaching adulthood. Most of those problems could persist throughout their adult life. One of the reasons for this problem is lack of adequate and accurate knowledge about sexual matters. Consequently, risky sexual behaviours such as unprotected sex, multiple sexual partnerships, and transactional sex are common among young people [1,2]. These behaviours predispose young people to the triple tragedy of sexually transmitted infections, including HIV/AIDS, unwanted teenage pregnancy and unsafe induced abortion $[3,4]$.

Parents play a critical role in the growth, development and sexual socialization of their children. Parental involvement through parent-child sexual communication (PCSC) presents education about sex and reproductive health to young people. Studies from the developed world [5-8], and sub-Saharan Africa [1,9,10] have been unequivocal regarding parents being the most dominant sex educators. In parent-child sexual communication, parents transmit sexual values, beliefs, information and expectations to their children with the aim of influencing sexual behaviours, attitudes and decision-making of their children [11-13]. Therefore, parental sexual communication to empower young people to manage the many challenges associated with youthfulness cannot be underestimated.

There is evidence that young people prefer to receive sexual information from their parents [14], yet only a few obtain such information from them $[1,15]$. Research suggests that sexuality communication can be a very useful intervention that encourages sexual responsibility among young people when the message is properly and comprehensively delivered [16].

In Ghana, parent-child sexual communication has not been well explored. The search of the literature revealed that very few studies had been conducted on parent-child sexual communication, including only four (4) published ones [17]. These studies were all selective in scope, coverage and assessment. For example, Adu-Mireku [18] only examined family communication about HIV/AIDS while Kumi-Kyeremeh and colleagues [19] investigated sexual communication by characterizing persons who have talked about sex-related matters with the adolescent.

In addition, most of these Ghanaian studies sought information from the perspective of young people only; the views of their parents were not considered. However, the views of both parents and children are critical for a balanced and comprehensive assessment of sexual communication.
Presently, very little is known in Ghana about studies that targeted both parents and their children to holistically examine sexual communication between parents and young people. Specifically, there is dearth of data on the type of topic discussed and frequency of parentchild sexual communication. PCSC was therefore explored to investigate the following question:

a) To what extent do parents in the Brong Ahafo region communicate with their children about sexual and reproductive health issues?

b) What are the possible topics parents are most likely to discuss in their sexual communication engagement with the children?

c) What are the triggers of parental sexual communication?

d) Is there any difference between a global single-item (Yes/No) measure of occurrence of communication and topic-by-topic assessment?

We hypothesized that the proportion of parents who communicate with young people would not be greater than 50\%; and that parents are more likely to report higher proportion of communication compared to young people's report.

\section{Methods}

\section{Study settings and period}

Data for this study came from a cross-sectional study conducted between January to March 2010, involving parents and their children aged 10-24 years in the Brong Ahafo region of Ghana. The region, located at the centre of the country, and lies within longitude $0^{\circ} 15^{\prime \prime} \mathrm{E}$ to $3^{\circ} \mathrm{W}$ and latitude $8^{\circ} 45^{\prime \prime} \mathrm{N}$ to $7^{\circ} 30^{\prime \prime} \mathrm{S}$. It has a population of $2,310,983$, of which $55.5 \%$ is rural [20]. The region shares boundaries with five other regions: the Northern region to the north, the Ashanti and Western regions to the south, the Volta Region to the east, and the Eastern region to the southeast. Also to the western frontier is La Cote d'Ivoire. Young people are about 761,179 (32.9\% of the total population of the region).

\section{Participants}

The study population was young people aged 10-24 years and their biological parents or parent-figures ${ }^{\mathrm{a}} \mathrm{de}$ facto residents in private homes in the region.

\section{Inclusion/exclusion criteria}

Study subjects were eligible to participate in the study if parent and child resided within a selected enumeration area; both parent and child pairs providing voluntary consent; aged between 10 years and 24 years; being either the biological parent or a parent figure who must have stayed continuously with the child for at least 
2 years prior to the survey. On the contrary, participants who were on a visit to the enumeration area during the data collection period. In addition, young people who were married were considered ineligible in the study.

\section{Sample size calculation}

The sample size was determined with the following parameters. Prevalence of parent-child sexual communication (p) was unknown, due to lack of appropriate information on sexual discussion from previous related studies in Ghana. Thus we assumed communication prevalence in the region will be about $50 \%$. We further assumed a 95\% confidence level (z), a margin of error (d) of $5 \%$ and a design effect (Deff) of 2, in order to improve the loss of precision arising from cluster sampling technique. Thus a minimum sample size of 768 was calculated using the population proportion formula follows:

$$
N=\frac{\left(z_{1-\mathrm{x} / 2}\right)^{2} p(1-p)}{d^{2}} \times \text { Deff }
$$

However, field data collection yielded 840 parent-child dyads, but 50 pairs of respondents were excluded for various reasons (refusal, incomplete information and being married), leaving 790 pairs with complete data for analysis.

\section{Sampling procedure}

The study employed both quantitative and qualitative methods. The sampling frame was the updated census EAs that were constructed by the Ghana Statistical Service for the 2000 Population and Housing Census in Ghana. The EAs consisted of or a section(s) of a town or a city, and in rural areas, one, two, or three adjoining smaller villages. Each EA was considered as a cluster, and was stratified into rural and urban components.

\section{Sampling for the quantitative component}

The quantitative component was a household-based survey. A two-stage stratified sampling technique was used. In the first stage, 52 EAs were selected across the 22 districts from a sampling frame consisting of 2,673 EAs in the region through a systematic procedure with probability proportional to size. The measure of size was the number of households in the EA.

The second stage entailed the selection of participants from households through the modified random walk method as had been used in previous studies $[21,22]$ as follows: EA maps and their descriptions were used to identify the boundaries of each EA. Thereafter, the various corners or key landmarks describing the EA were noted and numbered. These numbers were written on pieces of papers and one was chosen randomly. The corresponding corner/landmark was used as the random starting point. We selected 15-17 households per EA in conformity with previous sampling strategy employed by the Ghana Demographic and Health Survey [23]. After the first house/household, the next nearest house/household with eligible subjects was chosen for interview. This process continued until the target sample size for the EA was obtained.

\section{Selection of parent-child pairs}

Young people were the index respondents; and were used as leads for selecting parents. After determining a random starting point, the nearest even or oddnumbered house (EA specific) was entered and all young people aged 10-24 years were identified alongside their parents. In each house, only one household, that is, parent-child pair was eligible for interview. Therefore, all selected single-household houses with eligible young person automatically qualified for interviews. However, in houses with multiple households (for example compound houses), one household was randomly selected for interviews.

\section{Selection of mothers and fathers}

Both mothers and fathers were involved in the study; but in each household, only one of them was interviewed. Generally, the sex of parent was selected consecutively from one household to the other irrespective of the sex of the child. However, some fathers were difficult to reach as had been noted by previous studies [24]. In such cases, the mother was automatically interviewed, resulting in higher mother participation.

\section{Data collection procedures}

In each household, separate confidential interview was conducted in a convenient place for the parent-child dyad to avoid eavesdropping and to ensure openness and truthful responses. Parents were generally interviewed first, followed by the index child. This procedure enabled young people to freely discuss vital issues about themselves, and also ensured they were not apprehensive of parental presence. These measures ensured that interviewer-child interactions were devoid of possible information divulge, and also to minimise socially desirable response from children.

\section{Sampling for the qualitative component}

In-depth interview respondents were selected randomly from 13 out of the 22 districts. They were selected from the same EAs in which quantitative sample was drawn. In each selected EA, one household was selected randomly, and 26 parent-child participants who were not part of the quantitative survey were interviewed to elicit in-depth qualitative information. 


\section{Data and information sources}

Structured questionnaires were used to obtain quantitative data from parent-child dyads. Separate questionnaires solicited seemingly similar information from parents and young people. The questions were mainly extracted from previous related studies conducted mainly in developed countries including [25-31]. Questions that were alien to the Ghanaian cultural standards were adapted with cultural appropriateness. Just a few questions were developed from literature by the researchers.

The sets of questionnaires and the interview guides were forward and back translated from English to Twi (local language) by linguistics experts from the Linguistics Department of the University of Ghana. Amendments were made as necessary until final versions were obtained.

\section{Measures}

\section{Socio-demographic information}

Both parent and young people were asked directly to supply socio-demographic information such as age, sex, marital status, educational level, religious affiliation, employment status and family structure. In addition, young people were asked to provide information on how long they have stayed with their parents, closeness to parents, parent restriction and parent knowledge of child's whereabouts.

\section{Sex-related topics}

The study explored parent-child communication about 20 specific sex-related topics. Both parents and young people were asked to indicate whether they had ever had discussion on any of the twenty (20) specific sexual topics. The topics were categorized under three themes in reference to the procedure used by [26], namely: (1) biological/developmental (2) Sexual risk prevention or safety, and (3) experiencing sex.

\section{Communication about specific sexual topics}

Parents were presented with statements that asked whether they had ever talked to their children about 20 specific sex-related topics. The stem of the statements was "have you ever talked to your child about [topic] e.g. abstinence? The same statements phrased appropriately for young people sought to find out whether their parents had discussed the 20 sexual topics with them. The stem of the questions to young people was "has your mother/father ever talked to you about [topic] e.g. HIV/ AIDS. Response options for both dyads were $0=$ never, 1 = once, 2 = a few times, and $3=$ often. For the purposes of this analysis the responses from both parents and young people on these 20 items were recoded as $0=$ never [Never] and $1=$ ever [once, a few time, and often]. Thereafter, frequencies were computed for each the 20 topics separately for parents on one hand, and young people, comprising communication with mothers and fathers on the other hand.

\section{Prevalence of parent-child sexual communication}

The extent of sexual communication between parents and their children was assessed using two measures: (1) global measure and (2) detailed examination of 20 specific sexual topics (overall measure of communication). These procedures were used to facilitate holistic assessment of parent-child dyads' understanding of sexual communication. We assessed reports of parents and young people separately.

\section{Global measure of PCSC}

A direct global single-item (Yes/No) question was used to assess parent-child sexual communication. Parents were asked whether they had ever discussed sex-related matters with their child while young people were asked whether their parents had ever discussed sex-related matters with them.

\section{Overall measure of PCSC}

Three derived variables [(1) parent ever talk; child report of (2) mother ever talk and (3) father ever talk] were used to assess the overall prevalence of communication using parents' and young people's responses to the 20 sex-related items as described above. Parents were asked to report on how much they have talked to their children about 20 specific sex-related topics, while young people were asked to report how much their mothers and fathers had talked to them on the same topics. Response options $(0=$ never, $1=$ once, $2=a$ few times, and $3=$ often) for both dyads were converted into $0=$ never [Never] and 1 = ever [once, a few time, and often]. Different frequencies were run for these three groups. For the purposes of this study, a greater emphasis was placed on parents' report of sexuality communication since our prime interest was to measure parental efforts at sexual communication with their children. Children reports of communication were used to validate parental report.

\section{Triggers for initiating talks}

A single item phrased appropriately for parents and young people was used to find out key motivating factors that drive parents to initiate sexual communication action with their children. Parent-child dyads were asked directly to report the circumstance that led to sexual communicate. Response options were "Event-driven", "suspicion of sexual activity", "child asked a question", and "parent's own initiative". 


\section{Ethical considerations}

The study received ethical clearance from the Ghana Health Service Ethical Review Committee. Informed consent was obtained from all participants after the objectives and the methodology of the study had been explained to them. For literate participants, written informed consent was sought, while witnessed verbal consent was obtained from illiterate participants. Before obtaining consent, participants were assured of privacy and confidentiality, and voluntary participation was also stressed. For young people aged 10-17 years (minors), both parental consent and minor's assent were obtained before they participated in the study.

\section{Data management and analysis}

The quantitative data were independently captured by two trained data entry clerks using EpiData software version 3.1. Data entry screens with appropriate variable definitions, consistency checks and skipping patterns were designed separately to capture parent's and young people's questionnaires. The two entries were validated for accuracy and then exported from EpiData environment to IBM SPSS Statistics 20 (IBM Corp, Armonk, NY) and Stata 11.0 (Stata Corp, College Station, TX). We performed further cleaning and checks to ensure absolute data integrity.

Data analyses were performed with IBM SPSS Statistics 20 and Stata 11.0. We used frequency distributions and cross-tabulations to summarize socio-demographic data, the number of sexual topics discussed by parentchild dyads. The Pearson's Chi-square $\left(\chi^{2}\right)$ was used to examine differences in reports of sexual communication among parents and young people by sex as well as age groups. We assessed the level of agreement between parent-child dyads by performing a correspondence analysis using kappa statistics. Parent-child responses per each sexual topic were matched to determine dyads who agreed in responses as opposed to those who differed. We applied the benchmark developed by Landis and Koch, who maintain that agreement between two responses can be considered substantively significant when kappa reaches 0.4 [32]. This benchmark has been applied in previous parent-child study to undertake assessment of parent-child agreement [33]. Two comparisons were made between parent and child report of mother communication, and parent and child report of father communication.

Additionally, a series of two-sample z-test of proportions were conducted to determine whether there were significant differences between (a) the estimated prevalence of communication vs. actual prevalence of communication as reported in the present study, (b) Global measure of communication vs. topic-by-topic assessment of communication (c) parent report vs. child report of mother communication, (d) parent report vs. child report of father communication, and (e) various proportions reported separately by parents and children about the triggers of communication. In all statistical procedures, a $p$-value of 0.05 was used to determine statistical significance.

\section{Results}

\section{Distribution of the study participants}

A summary statistics of socio-demographic characteristics of the 790 parent-child dyads are reported in Table 1. The study comprised $53.9 \%$ rural and $46.1 \%$ urban residents. More than half $(56.2 \%)$ of the parent sample were mothers, and the about $77 \%$ were married. Parents' ages ranged from 26 years to 76 years, with a mean age of 47.1 years $(S D=10.0)$. Fathers were 4 years older than mothers $(p<0.001)$. About two-thirds of the parents attended some school, of which half (50.5\%) ended at the basic level.

The young people sample comprised 52\% females. Young people's ages ranged from 10 years to 24 years with a mean age of 16.7 years $(S D=4.0)$. There was no statistically significant age different between daughters and sons. About one-third (33.4\%) of young people were young adolescents aged $10-14$ years, $39.1 \%$ older adolescents $15-19$ years old, and $27.5 \%$ young adults aged 20-24 years. About two-thirds (67.2\%) live with both parents.

\section{Parent-child sexual communication}

The extent of sexual communication between parents and their children was assessed using a global measure of sexual communication as well as detailed examination of 20 specific sexual topics. These procedures were used to facilitate holistic assessment of parent-child dyads' understanding of sexual communication. We assessed reports of parents and young people separately.

\section{Global measure of parent-child sexual communication}

Using a global single-item (Yes/No) measure of parentchild sexual communication, $74.4 \%$ of parents indicated they had ever communicated with their children on sexual issues while $72.8 \%$ of young people reported that their parents had ever talked to them about sexual issues. Parental sex difference was not statistically significant, but among young people, more daughters than sons reported discussion with their parents $(76.3 \%$ vs. $69.1 \%, p<0.05$.). When asked whether it was important for parents to talk to them about sexual and reproductive health issues, almost all young people $(98.8 \%)$ answered in the affirmative.

\section{Overall measure of sexual communication}

Assessment of the 20 specific sexual topics revealed that about $82.3 \%$ (650/790) of parents had ever talked ${ }^{\mathrm{b}}$ about 
Table 1 Socio-demographic characteristic of parents and young people

\begin{tabular}{|c|c|c|c|c|c|c|}
\hline \multirow[t]{2}{*}{ Characteristics } & \multicolumn{3}{|l|}{ Parent } & \multicolumn{3}{|l|}{ Young people } \\
\hline & Total $(\mathrm{N}=790)$ & Mother $(\mathrm{N}=444)$ & Father $(N=346)$ & Total $\mathrm{N}=790$ ) & Daughters $(\mathrm{N}=405)$ & Sons $(N=385)$ \\
\hline Age in years, $M(S D)$ & $47.1(10.0)$ & $45.2(10.3)$ & $49.5(9.2)^{* * *}$ & $16.7(4.0)$ & $16.6(3.8)$ & $16.8(4.0)$ \\
\hline \multicolumn{7}{|l|}{ Place of residence $\%$} \\
\hline Rural & 53.9 & 49.8 & $59.2^{*}$ & 53.9 & 50.9 & 57.1 \\
\hline Urban & 46.1 & 50.2 & 40.8 & 46.1 & 49.1 & 42.9 \\
\hline \multicolumn{7}{|l|}{ Educational level \% } \\
\hline No Education & 32.9 & 39.9 & $24.0^{* * *}$ & 2.5 & 4.0 & $1.0^{*}$ \\
\hline Basic & 50.5 & 48.0 & 53.8 & 76.1 & 77.0 & 75.1 \\
\hline$\geq$ Secondary & 16.6 & 12.2 & 22.3 & 21.4 & 19.0 & 23.9 \\
\hline \multicolumn{7}{|c|}{ Religious affiliation \% } \\
\hline Christian & 78.6 & 82.4 & $73.7^{* *}$ & 81.0 & 83.0 & 79.0 \\
\hline Muslim & 13.0 & 12.4 & 13.9 & 12.4 & 12.1 & 12.7 \\
\hline Traditionalist & 1.3 & 0.5 & 2.3 & 0.5 & 0.5 & 0.5 \\
\hline No religion & 7.1 & 4.7 & 10.1 & 6.1 & 4.4 & 7.8 \\
\hline \multicolumn{7}{|l|}{ Family structure \% } \\
\hline Both parents & 67.2 & 53.8 & $84.4^{* * *}$ & 67.2 & 62.7 & $71.9^{* * *}$ \\
\hline Mother only & 21.1 & 36.0 & 2.0 & 21.1 & 25.2 & 16.9 \\
\hline Father only & 5.1 & 1.1 & 10.1 & 5.1 & 2.7 & 7.5 \\
\hline Grandparents & 6.6 & 9.0 & 3.5 & 6.6 & 9.4 & 3.6 \\
\hline
\end{tabular}

Marital status \%

$\begin{array}{llll}\text { Single } & 2.5 & 2.7 & 2.3^{* * *} \\ \text { Married } & 77.5 & 68.7 & 88.7 \\ \text { Divorced/separated } & 19.0 & 26.8 & 9.0 \\ \text { Cohabiting } & 1.0 & 1.8 & 0.0 \\ \text { Occupation \% } & & & \\ \text { Unemployed } & 5.2 & 7.7 & 2.0^{* * *} \\ \text { Farmer } & 53.3 & 47.1 & 61.3 \\ \text { Trade/artisan } & 25.5 & 32.4 & 18.8 \\ \text { Formal sector } & 15.1 & 12.8 & 17.9\end{array}$

Age group in years \%

\begin{tabular}{|c|c|c|c|}
\hline $10-14$ & 33.4 & 32.8 & 34.0 \\
\hline $15-19$ & 39.1 & 41.7 & 36.4 \\
\hline $20-24$ & 27.5 & 25.4 & 39.6 \\
\hline \multicolumn{4}{|c|}{ Stayed with parents \% } \\
\hline Continuous stay & 85.3 & 81.7 & $89.6^{* *}$ \\
\hline Partial stay & 14.7 & 18.5 & 10.6 \\
\hline
\end{tabular}

Note: Statistical test compares differences between mothers and fathers for each variable. ${ }^{*} P<0.05$. ${ }^{* *} P<0.01$. ${ }^{* *} P<0.001$.

sexual issues with their children. Child report showed that $78.8 \%(617 / 783)$ of mothers had discussed sexual communication while $53.5 \%(374 / 699)$ of fathers had talked to their children about sex as shown in Figure 1. A two-sample z-test of proportions found significant difference between the $50 \%$ assumed prevalence of parental communication and actual (82.3\%) prevalence of parent-child communication (mean difference $=0.323$; $95 \%$
CI [0.279 - 0.367], $p<0.001)$. Thus the null hypothesis was rejected. Furthermore, the reports of communication from parents and by children (mother and father) were compared using z-test. A test of proportions between parents reported prevalence of communication and child report of father communication was statistically significant ( mean difference $=0.288 ; 95 \%$ CI $[0.242-0.0 .334]$, $p=0.079)$. However, there was no difference in proportions 


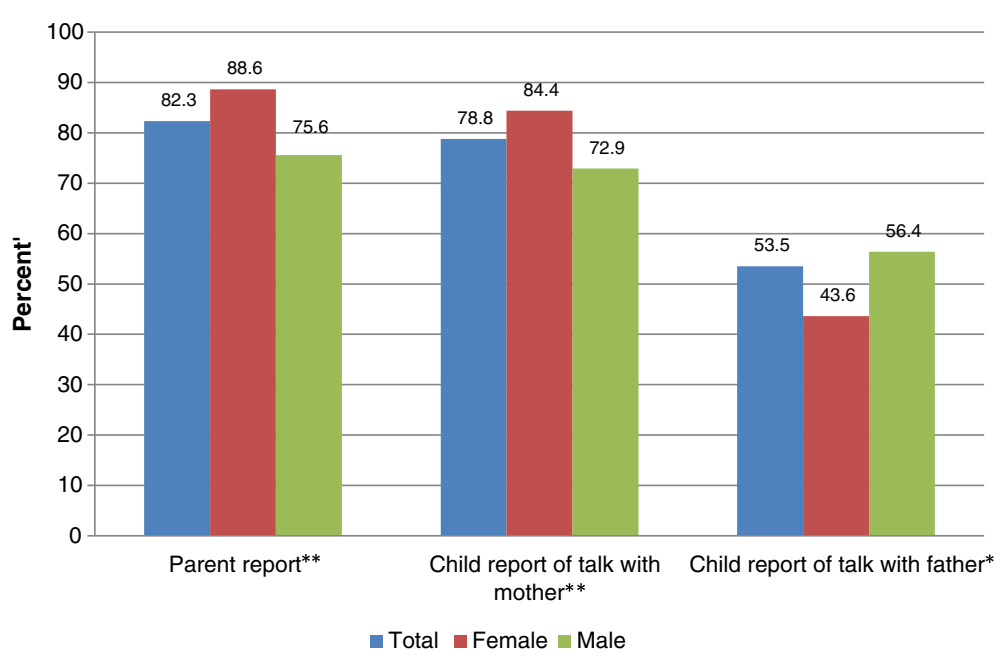

Figure 1 Parents and young people sex differences in report of overall communication prevalence. Note: Chi-square compares differences between females and males by communication. ${ }^{*} p<0.01,{ }^{* *} p<0.001$.

between parents reported communication and child report of mother communication (mean difference $=0.035$; $95 \%$ CI $[-0.004-0.074], p=0.079)$.

Chi-square tests showed significant differences between mothers and fathers, as well as daughters and son's report of communication.

\section{Comparison between global measure of PCSC and overall topic analysis measure}

We used a two sample z-test of proportions to evaluate the difference in proportions between the frequency of global communication and frequency of the overall topic analysis. We found a statistically significant difference between the frequency of communication using global measure and the overall topic analysis measure (mean difference $=0.079 ; 95 \%$ CI $[0.038-0.119], p<0.001$. This clearly suggests that global measure of communication reports a lower amount of communication.

\section{Triggers of parental sexual communication}

Figure 2 presents the distribution of the various triggers of parental sexual communication as reported by parents and children. Parent-child pairs were independently interviewed and responses were compiled and compared

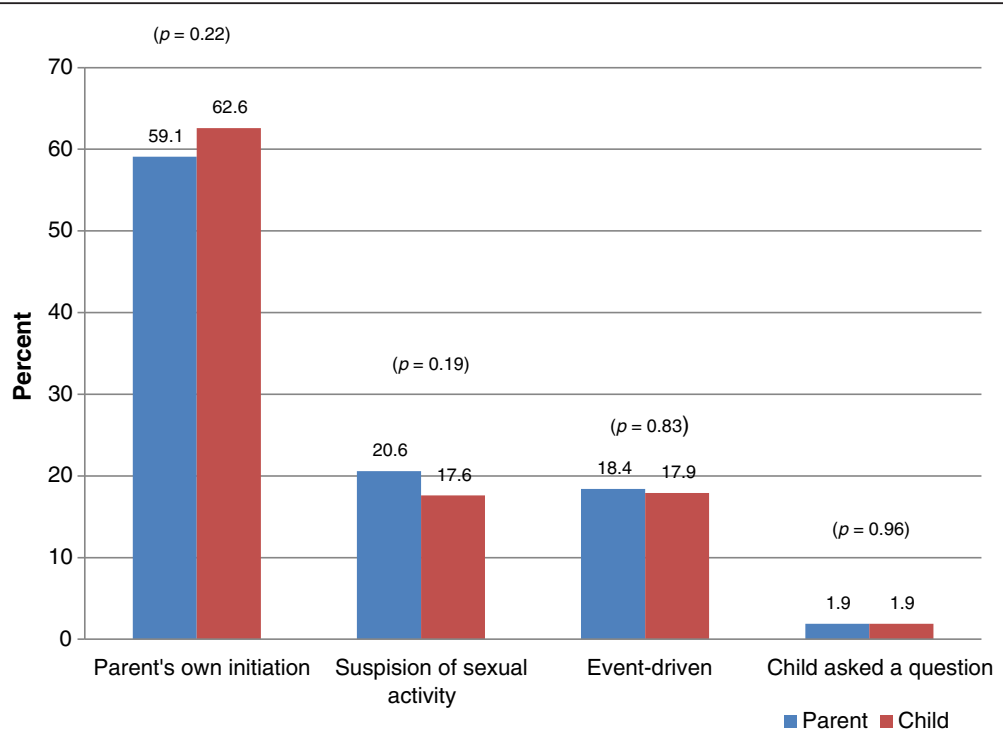

Figure 2 Comparison of reason why parents initiated sexual talks as reported by parents and young people. Note: The figures in parenthesis on top of each pair of bars represent $p$-values for the difference in proportions for each pair of parent-child responses. 
reason-by-reason. Figure 2 presents reasons that triggered parents initiate sexual talks with their children. Comparison of the two sets of responses from parents and children reveals a general trend. Independently, more than half of parents (59.1\%) and children (62.6\%) indicated that sexual communication was triggered on parent's own initiative [Figure 2]. A $z$-test of proportions revealed no differences in reports from parents and children. The $p$-values for the various response categories are reported on-top of each pair of bars [Figure 2].

Table 2 presents Chi-square analyses examining parent and child reports of triggers of sexual communication selected background variables of child. The results show that child's age and connectedness to parents were significantly associated with both parent and child reports of triggers of communication. Both reports indicate that parents are more likely initiate sexual talks on their own initiative with young adolescents 10-14 years compared with young people aged 20-24 years. In addition, sex of child and length of stay with parents were related with triggers of communication from child viewpoint (Table 3).

In-depth interview with parents and young people confirmed that more parents engage children in sexual talks largely on parents' own initiation. The following statements support the overwhelming reason that parental sexual communication is started on parent's own initiative:

"...because she is growing into womanhood, she must know and be able to imitate me as a mother, so on my own accord had to teach her things relating to her sexual life as well as household chores" (Urban mother, aged 47 years).

"Premarital sex brings hardships in the family, and girls suffer most compared to boys..., so it is very important to let them know about these things (sexual issues), because if you do not tell them they will go out there and bring you all sorts of irresponsible behaviours with their untold hardships" (Rural mother, aged 38 years).

"My daughter looks older in stature, so I felt she should know about these things... so that no man can deceive her" (Rural mother, aged 36 years).

"In the olden days, young people were able to abstain from sex until marriage, but these days, no! So I advised him to emulate me and stay away from girls and bad boys" (Rural father, aged 60 years).

Table 2 Association between parent and child perspectives on the triggers of sexual communication by selected background characteristics of child

\begin{tabular}{|c|c|c|c|c|c|c|c|c|}
\hline \multirow[t]{2}{*}{ Variable } & \multicolumn{2}{|c|}{ Parent's own initiation } & \multicolumn{2}{|c|}{ Suspicion } & \multicolumn{2}{|c|}{ Event driven } & \multicolumn{2}{|c|}{ Child asked a question } \\
\hline & Parent & Child & Parent & Child & Parent & Child & Parent & Child \\
\hline Sex of child & * & $*$ & & * & & * & & * \\
\hline Female & 58.6 & 57.6 & 21.3 & 19.4 & 18.8 & 20.1 & 1.9 & 2.9 \\
\hline Male & 59.7 & 68.4 & 19.8 & 15.4 & 18.4 & 15.4 & 1.9 & 0.8 \\
\hline Age group & $* * *$ & $* * *$ & $* * *$ & $* * *$ & $* * *$ & $* * *$ & $* * *$ & $* * *$ \\
\hline $10-14$ & 72.3 & 84.9 & 5.0 & 4.1 & 19.9 & 9.6 & 2.8 & 1.4 \\
\hline $15-19$ & 52.3 & 56.6 & 24.8 & 20.1 & 20.5 & 21.7 & 2.3 & 1.6 \\
\hline $20-24$ & 58.5 & 52.8 & 26.6 & 25.0 & 14.4 & 19.4 & 0.5 & 2.8 \\
\hline Parent connectedness & * & * & * & * & * & * & * & * \\
\hline Not close & 40.0 & 37.5 & 20.0 & 25.0 & 40.0 & 37.5 & 0.0 & 0.0 \\
\hline Somewhat close & 54.9 & 58.4 & 23.2 & 21.5 & 21.5 & 20.1 & 0.4 & 0.0 \\
\hline Very close & 62.5 & 65.8 & 18.9 & 14.9 & 15.7 & 16.1 & 2.9 & 3.2 \\
\hline \multicolumn{9}{|l|}{ Place of residence } \\
\hline Rural & 58.7 & 61.9 & 22.2 & 19.5 & 18.1 & 17.9 & 1.0 & 0.7 \\
\hline Urban & 59.6 & 63.4 & 18.8 & 15.3 & 18.8 & 17.9 & 2.9 & 3.4 \\
\hline Stay with parent & & $* *$ & & $* *$ & & $* *$ & & $* *$ \\
\hline Partial stay & 59.0 & 54.7 & 22.9 & 23.3 & 15.7 & 16.3 & 2.4 & 5.8 \\
\hline Continuous stay & 59.1 & 64.0 & 20.2 & 16.6 & 18.8 & 18.2 & 1.8 & 1.2 \\
\hline
\end{tabular}

Note: Statistical test compares differences between mothers and fathers for each variable. ${ }^{*} P<0.05$. ${ }^{* *} P<0.01$. ${ }^{* *} P<0.001$. 
Table 3 Parent and young people reports of discussion of specific sexual topics and the level of agreement in both reporters

\begin{tabular}{|c|c|c|c|c|c|}
\hline \multirow[t]{3}{*}{ Sexual topic } & \multirow{3}{*}{$\begin{array}{l}\text { Parent report } \\
\text { Discussion with child N=781-790* } \\
\text { n (\%) }\end{array}$} & \multicolumn{4}{|c|}{ Young people report } \\
\hline & & \multicolumn{2}{|c|}{ Mother discussion $N=780-783^{*}$} & \multicolumn{2}{|c|}{ Father discussion $N=690-696^{*}$} \\
\hline & & n (\%) & Kappa $^{\ddagger}$ & n (\%) & Kappa $^{\ddagger}$ \\
\hline \multicolumn{6}{|l|}{ Biological/developmental } \\
\hline Physical development & $436(55.5)$ & $396(50.6)$ & 0.53 & $126(18.2)$ & 0.24 \\
\hline Menstruation/wet dream & $260(63.3)$ & $298(38.4)$ & 0.51 & $43(6.2)$ & 0.02 \\
\hline Puberty & $443(56.3)$ & $413(52.8)$ & 0.53 & $123(17.7)$ & 0.23 \\
\hline Reproduction/having babies & $51(6.5)$ & $48(5.8)$ & 0.42 & $3(0.4)$ & -0.01 \\
\hline Masturbation & $18(2.5)$ & $15(1.9)$ & 0.04 & $7(1.0)$ & 0.25 \\
\hline \multicolumn{6}{|l|}{ Sexual risk prevention or safety } \\
\hline Prevention of STDs & $445(56.3)$ & $380(48.7)$ & 0.53 & $194(27.9)$ & 0.33 \\
\hline Prevention of HIV/AIDS & $485(61.5)$ & $421(53.8)$ & 0.54 & $228(32.8)$ & 0.32 \\
\hline Abstaining from sex until marriage & $581(73.6)$ & $544(69.5)$ & 0.60 & $320(46.0)$ & 0.34 \\
\hline Use of condoms & $73(9.3)$ & $68(8.7)$ & 0.45 & $35(5.1)$ & 0.29 \\
\hline Contraceptives & $41(5.2)$ & $39(5.0)$ & 0.45 & $7(1.0)$ & 0.22 \\
\hline Pregnancy & $66(8.4)$ & $82(10.5)$ & 0.36 & $14(2.0)$ & 0.09 \\
\hline Abortion & $168(21.3)$ & $167(21.3)$ & 0.62 & $72(10.2)$ & 0.41 \\
\hline Consequences of premarital sex & $380(48.3)$ & $357(45.6)$ & 0.69 & $213(30.6)$ & 0.48 \\
\hline Substance use & $315(39.9)$ & $302(38.6)$ & 0.63 & $199(28.6)$ & 0.56 \\
\hline \multicolumn{6}{|l|}{ Experiencing sex } \\
\hline Sexual feelings & $51(6.5)$ & $35(4.5)$ & 0.26 & $9(1.3)$ & 0.10 \\
\hline When to start sexual intercourse & $150(19.0)$ & $127(16.2)$ & 0.60 & $61(8.8)$ & 0.37 \\
\hline Choosing sexual partners & $90(11.4)$ & $77(9.8)$ & 0.56 & $27(3.7)$ & 0.43 \\
\hline How to handle sexual pressure & $59(7.2)$ & $48(6.1)$ & 0.41 & $9(1.3)$ & 0.22 \\
\hline Safer sex & $62(7.9)$ & $54(6.9)$ & 0.52 & $14(2.0)$ & 0.26 \\
\hline Homosexuality & $42(5.2)$ & $37(4.7)$ & 0.56 & $29(4.2)$ & 0.47 \\
\hline
\end{tabular}

Note: *Sample sizes for the various topics vary due to sporadic missing values.

${ }^{\ddagger}$ Kappa compares agreement between (a) parent report vs. child's report of mother communication, and (b) parent report vs. child's report of father communication.

\section{Commonly discussed sexual topics by parents}

Presented in Table 3 are the proportions of parent-child dyads reports of discussion on each of the 20 specific sexual topics. Parental discussions with young people on specific topics ranged from $5.2 \%-73.6 \%$. On the other hand, young people's report indicates that mother-discussed topics ranged between $1.9 \%$ and $69.5 \%$, while father discussed topics ranged from $0.4 \%$ to $46.0 \%$. Based on the proportions, four main patterns of PCSC are clearly discerned, First, parents' tended to report higher levels of communication on nearly all sexual topics, compared with the proportions reported by young people. Secondly, young people reported higher proportions of communication with mothers than fathers. Third, the data show that parents generally talk about sexual risk prevention and developmental topics compared with experiential sex topics. Frequently discussed topics (in bold type face) include: (1) abstinence, HIV/AIDS, STDs, consequences of premarital sex and substance use, menstruation (girls), physical development and puberty. For instance, both parents and young people reported sexual abstinence as the most widely discussed topic. Whereas $73.6 \%$ of parents reported they had discussed abstinence with their children, child report indicated that $69.5 \%$ of mothers and $46.0 \%$ of fathers had talked to them about abstinence. Apart from topic analysis, we found that higher proportions of parents communicate more with daughters than sons on almost all topics, except for substance use.

Finally, both parents hardly discuss contraceptive and experiential sex topics with their children. In nearly half (45\%) of the 20 topics, very few (less than 10\%) parents reported they had ever discussed topics such as masturbation, condom use, contraception and pregnancy with 
their children. A comparable trend (same topics and almost the same order) was observed regarding child's report of communication with parents (see Table 3).

Evidence from the qualitative interviews supports the above results. Topics that were frequently discussed included abstinence STDs, HIV/AIDS and premarital sex. The following statements illustrate the findings:

"I have repeatedly told her to abstain from premarital sex to avoid teenage pregnancy, STDs and AIDS; because AIDS is deadly,...that it is better to abstain to avoid diseases, because AIDS and other STD's are not written on the faces of infected persons" (Rural mother, aged 47 years).

Reports from young people corroborated parents' reports. The following are some quotations:

"Among the topics my mother taught me were how to protect myself from STDs like HIV/AIDS and Gonorrhoea. She also advised me to abstain from sex to avoid unwanted pregnancy and abortion" (Urban young boy, aged 16 years).

"My mother talked to me about menstruation when I was about 13 years. She has also advised me to protect myself from HIV/AIDS by abstaining from sex or use condom during sex" (Urban young girl, aged 22 years).

\section{Parent-child agreement}

Table 3 shows the kappa coefficients for parents versus child report of mother communication on one hand, and parent versus child report of father communication with father. There were moderate to substantial agreement for parents vs. child report of mother communication. Seventeen (17) out of the 20 topics produced kappa coefficients ranging from $0.41-0.69$. However, parent and child reports of father sexual conversation showed fair agreement, as only 5 out the 20 topics fell in the moderate agreement benchmark with reported kappa ranging from $0.41-0.56$ (Table 3 ).

\section{Discussion}

Our study focused on assessing the pattern of PCSC, sexual topics parents are generally likely to discuss with their children, and to examine triggers of sexuality communication. The study found that higher proportion of parents in the Brong Ahafo region communicates with their children about sexual and reproductive health issues. Both parent and child reports indicate that over $70 \%$ of parents had ever discussed (at least one topic) an aspect of sexual and reproductive health matters with their children. This finding is remarkable and very encouraging in the context of the Ghanaian cultural milieu, where traditionally, sexual communication is perceived to be a taboo and preserve for adults [34]. This probably may challenge the notion that sexual communication in the African context is uncommon [35].

Though most Ghanaian societies frown on open discussion of sexual issues, it does not necessarily imply that parents never talk about them at all. Discussion on them takes place as and when necessary, taking into consideration the cultural context.

Earlier studies in some African countries found a moderate amount of PCSC $[4,36]$. However, recent studies have found higher levels of parent-child communication. For example, Opara and colleagues [37] found that about $65 \%$ of mothers had discussed sexuality issues with their children at some point in time, while another Lagos-based study reported PCSC prevalence of $69 \%$ [38]. The present study affirms recent trends in PCSC in some parts of African.

Assessment of communication on specific sex-related topics revealed that $82.3 \%$ of parents have discussed at least a sex topic with their children, while a global singleitem measure showed $74.4 \%$ of parents had done so. It appears that global single-item measure of PCSC seems to underestimate the true amount of sexual communication compared with assessment of individual sexual and reproductive health topics. The statistically significant mean difference of about 8.0 percentage difference might mean that some parents may unconsciously discuss sexual communication but rather attribute such talks as part of general communication. It is possible some parents may consider only communication episodes in which they formally sat their children down for the talks; and may discount most sexual messages that were delivered informally in censure to the child's misbehavior.

This finding supports the evidence in the sexual communication literature that global single-item measures often result in interpretation bias $[39,40]$, and therefore may fail to capture the all aspects of sexual communication. Similar to reports of other scholars [41,42], our study found that topic-specific communication is more effective and more preferred compared with global forms of communication.

Various triggers fuel parental communication. We found that $62.6 \%$ of parents and $59.1 \%$ of children unanimously cited "parents' own initiation" as the dominant reason for parental communication action (Figure 2). The trend of responses from both participants (Figure 2) suggests agreement in reports between parents and their children. Various rationales were advanced as the motivation for pursuing sexual talks with children. Parents generally are concerned about the safety of their children. In particular, parents believe that their daughters, especially, are prone to trickeries of men, thus they need to be equipped with sex education. 
We found that parental communications are directed towards a few topics. Six out of the 20 topics, that are commonly discussed by parents include abstinence, menstruation (girls), HIV prevention, STD prevention, puberty and physical development. These findings are consistent with past studies that examined discussion of sexual topics $[26,43,44]$. Even though this study did not explore the reasons why parents frequently discuss these topics, the general trend suggests parents' concern about adolescent sexual safety.

Specifically, communication about abstinence from sex emerged as the common topic parents frequently discussed with their children. Nearly three-quarters (73.6\%) of parents indicated they had discussed abstinence. Reporting abstinence as the commonly discussed topic is consistent with the literature $[45,46]$. For example, Tesso and colleagues [46] reported in their study that $84.6 \%$ young people in West Ethiopia had discussed abstinence.

Across all the 20 topics, parents reported higher proportion of communication compared to young people. As other studies have found, mothers communicate relatively more to both daughters and sons than fathers $[47,48]$. the different proportions reported by parents and young people imply that parent-child dyads have different estimates of how often sexual communication occurs between them, though they largely agree on topics discussed.

Unlike previous studies $[39,47]$, our study found substantive agreement in reports of communication between parent-child dyads. At all levels of talks, mothers and children, exhibited substantial level of agreements compared to father-child discussions (Table 3). The higher level of congruence in topics discussed indicates that parents and their children were all reporting similar probabilities of occurrence of communication about the various topics. This is consistent with other studies [43], suggesting that perhaps, children are internalizing parental sexual messages. Evidence from the literature suggests that parents have a tendency to "overestimate" the degree of communication with children, while children may "underestimate" the amount of discussion parents had had with them [49]. In spite of this trend of reporting, there was no mechanism to assess from the data whether parents overestimated their report of discussion or children underestimated on their part.

The following strengths are noted in the study. First, unlike many previous African studies on PCSC that examined communication from either parent or child perspective only $[1,19,37,38]$, our study considered reports of communication from both parents and children. It is one of the few in Ghana to systematically explore parent-child dyads' perspectives on communication about sexual and reproductive health issues. Examining PCSC from parentchild perspectives simultaneously is important for holistic and an unbiased assessment of sexuality communication. Secondly, both sexes of parents and young people were studied, and thus provided greater insights into PCSC. This is an improvement over the many previous designs that examined sexual communication from the perspective of either parents or young people or mothers versus daughters/son. In addition, many of the previous studies covered only a limited scope of sexual communication; for example, a single topic, such as HIV/AIDS [18]. The present study comprised detailed analysis of 20 specific sexual topics, and compared with a global single item measures. The results emphasize the importance of topicby-topic analysis of assessing PCSC.

We note some limitations in the study. Firstly, the data came from a cross-sectional study; and PCSC variables were measured retrospectively. Thus the study may suffer from recall bias since there was no mechanism to independently verify respondents' self-reported data. However, the substantive level of correspondence between parent and child reports of communication suggests that recall bias may not be a serious problem that might refute the findings in this study. Finally, the study was conducted in the Brong Ahafo region only, out of the 10 regions of Ghana. The findings may not necessarily represent the general views of parents and young people in Ghana.

The findings from this study have implication for public health programming and research on young people sexual and reproductive health. First, the study provides information on the common topics parents are likely to discuss in sexual communication engagements with children. Thus sex educational programmes ought to target parents to expand sexual communication to cover more topics including condom and contraceptive use, which are seldom discussed. This is particularly important since condoms and contraceptive use play crucial roles in sexual risk prevention practices. Second, the study provides baseline data for future studies on PCSC. In particular, the method of assessing communication frequency by topic-by-topic analysis is could employed by in future studies since it provides a better estimate than global single-item measure of communication.

Our study explored only a few dimensions of PCSC, including the pattern, frequency and topics discussed. Future studies should consider assessment of content and quality of PCSC to examine what specific messages parent transmit to their children during sexual talks rendezvous.

\section{Conclusions}

This study has demonstrated that majority of parents in the Brong Ahafo region of Ghana engage their children in sex-related talks, but much of the conversations is concentrated on a few sexual topics like abstinence, menstruation HIV/AIDS, STDs and puberty. Mothers 
talk more about sexual and reproductive health issues with theirs children than fathers. Strategies need to be devised to encourage father involvement in parent child sexual communication.

\section{Endnotes}

${ }^{a}$ An adult who is not the biological parent, but whom young people describe as being like a mother or father to them, and with whom they stay with.

${ }^{\mathrm{b}}$ Parent has discussed at least one sexual topic with the child.

\section{Abbreviations}

EAs: Enumeration areas; GSS: Ghana Statistical Service; HIV/AIDS: Human immunodeficiency virus/acquired immune deficiency syndrome; IBM SPSS: International business machine statistical package for social sciences; PCSC: Parent-child sexual communication; STDs: Sexually transmitted diseases; Vs.: Versus.

\section{Competing interests}

The authors declare that they have no competing interests.

\section{Authors' contributions}

AAM conceptualized and designed the study, conducted preparatory field works, collected data, conducted data analysis, drafted the manuscript and performed interpretation of data; CJM was involved in revisions of the research proposal, data collection and analysis, interpretation of data, and revision of the manuscript for publication; GQA was involved in revisions of the research proposal, and analysis, and revision of the manuscript for publication; KO contributed to data analysis, data interpretation and revisions of the manuscript for critical intellectual content; and RKOA was involved in the conceptualization of the study, revisions of the research proposal, and revision of the manuscript for critical intellectual content. All authors read and approved the final manuscript.

\section{Acknowledgements}

We acknowledge with gratitude all parent-child dyads who participated in this study, and also our research assistants for their dedication. The entire study was funded by the Bill and Melinda Gates Foundation (Grant number: 50786) through the Ghana-Michigan Collaborative Health Alliance for Reshaping Training, Education and Research (CHARTER). Ghana-Michigan CHARTER was a collaborative research and capacity building initiative between the University of Michigan, the Ministry of Health of Ghana, the University of Ghana, and the Kwame Nkrumah University of Science and Technology to address and strengthen human resources for health in Ghana. The funders did not play any role in connection with this study. All opinions expressed in this article are the authors'.

\section{Author details}

'Department of Population, Family, \& Reproductive Health, School of Public Health, College of Health Sciences, University of Ghana, P.O. Box LG 13, Accra, Ghana. ${ }^{2}$ Association of African Universities, P.O. Box AN 5744, Accra, Ghana. ${ }^{3}$ Family Health Division, Ghana Health Service, Private Mail Bag, Ministries, Accra, Ghana. ${ }^{4}$ RHI Medical Centre, Amanokrom, P.O. Box 134 Mampong-Akuapem, Eastern Region, Ghana. ${ }^{5}$ School of Applied Sciences, Central University College, Miotso Campus, P.O. Box 2305, Tema, Ghana.

\section{Received: 2 April 2014 Accepted: 5 February 2015}

\section{Published online: 07 March 2015}

\section{References}

1. Babalola S, Tambashe BO, Vondrasek C. Parental factors and sexual risk-taking among young people in Cote d'Ivoire. Afr J Reprod Health. 2005;9(1):49-65.

2. Olugbenga-Bello Al, Adebimpe WO, Abodunrin OL. Sexual risk behaviour among in-school adolescents in Public Secondary schools in a Southwestern City in Nigeria. Int J Health Res. 2009;2(3):243-51.
3. Lloyd CB: The role of schools in promoting sexual and reproductive health among adolescents in developing countries. In: Poverty, Gender, and Youth Working Papers No 6. New York: Population Council; 2007.

4. Izugbara CO. Home-based sexuality education: Nigerian parents discussing sex with their children. Youth Society. 2008;39(4):575-600.

5. Jaccard J, Dodge T, Dittus P. Parent-adolescent communication about sex and birth control: a conceptual framework. New Dir Child Adolesc Dev. 2002;97:9-41.

6. Dilorio C, Pluhar E, Belcher L. Parent-child communication about sexuality: a review of the literature from 1980-2002. J HIV AIDS Prev Educ Adolesc Child. 2003;5(3\&4):7-32.

7. Turnbull T, van Wersch A, van Schaik P. A review of parental involvement in sex education: the role for effective communication in British families. Health Educ J. 2008;67(3):182-95.

8. Beckett MK, Elliott MN, Martino S, Kanouse DE, Corona R, Klein DJ, et al. Timing of parent and child communication about sexuality relative to children's sexual behaviors. Pediatrics. 2010;125(1):34-42.

9. Namisi FS, Flisher AJ, Overland S, Bastien S, Onya H, Kaaya S, et al. Sociodemographic variations in communication on sexuality and HIV/AIDS with parents, family members and teachers among in-school adolescents: a multi-site study in Tanzania and South Africa. Scand J Public Health. 2009;37 Suppl 2:65-74.

10. Biddlecom A, Awusabo-Asare K, Bankole A. Role of parents in adolescent sexual activity and contraceptive use in four African countries. Int Perspect Sex Reprod Health. 2009;35(2):72-81.

11. Jerman P, Constantine NA. Demographic and psychological predictors of parent-adolescent communication about sex: a representative statewide analysis. J Youth Adolesc. 2010;39(10):1164-74.

12. Lefkowitz ES, Stoppa TM. Positive sexual communication and socialization in the parent-adolescent context. New Dir Child Adolesc Dev. 2006;112:39-55.

13. Eisenberg ME, Sieving RE, Bearinger $L H$, Swain C, Resnick MD. Parents' communication with adolescents about sexual behavior: a missed opportunity for prevention? J Youth Adolesc. 2006;35(6):893-902.

14. Clawson CL, Reese-Weber M. The amount and timing of parent-adolescent sexual communication as predictors of late adolescents sexual risk-taking behaviours. J Sex Res. 2003;40(3):256-65.

15. Somers CL, Paulson SE. Students' perceptions of parent-adolescent closeness and communication about sexuality: relations with sexual knowledge, attitudes, and behaviors. J Adolesc. 2000;23(5):629-44.

16. Undie C, Crichton J, Zulu EM. Metaphors we love by: conceptualizations of sex among young people in Malawi. Afr J Reprod Health. 2007;11(3):221-35.

17. Bastien $S$, Kajula L, Muhezi W. A review of studies of parent-child communication about sexuality and HIV/AIDS in sub-Saharan Africa. In: Reproductive Health, vol. 8. 2011

18. Adu-Mireku S. Family communication about HIV/AIDS and sexual behaviour among senior secondary school students in Accra, Ghana. Afr Health Sci. 2003;3(1):7-14

19. Kumi-Kyereme A, Awusabo-Asare K, Biddlecom A, Tanle A. Influence of social connectedness, communication and monitoring on adolescent sexual activity in Ghana. Afr J Reprod Health. 2007;11(3):133-47.

20. Ghana Statistical Service. Population and housing census: sumary report of final results. Accra: Ghana Statistical Service; 2010. p. 2012.

21. Milligan $P$, Njie A, Bennett $S$. Comparison of two cluster sampling methods for health surveys in developing countries. Int J Epidemiol. 2004;33(3):469-76.

22. Magnani R. Sampling guide. Washington, DC: Food and Nutrition Technical Assistance Project (FANTA); Academy for Educational Development; 1997. p. 1-52.

23. GSS, NMIMR, ORC Macro. Ghana demographic and health survey 2003. Calverton, Maryland: GSS, NMIMR and ORC Macro; 2004.

24. Costigan C, Cox M. Fathers' participation in family research: Is there a self-selection bias? J Fam Psychol. 2001;15:706-20.

25. Guilamo-Ramos V, Jaccard J, Dittus P, Bouris AM. Parental expertise, trustworthiness, and accessibility: parent-adolescent communication and adolescent risk behavior. J Marriage Fam. 2006;68:1229-46.

26. Atienzo EE, Walker DM, Campero L, Lamadrid-Figueroa H, Gutiérrez JP. Parent-adolescent communication about sex in Morelos, Mexico: Does it impact sexual behavior? Eur J Contracept Reprod Health Care. 2009;14(2):111-9.

27. Guilamo-Ramos V, Jaccard J, Dittus P, Collins S. Parent-adolescent communication about sexual intercourse: an analysis of maternal reluctance to communicate. Health Psychol. 2008;27(6):760-9. 
28. Dutra R, Miller KS, Forehand R. The process and content of sexual communication with adolescents in two-parent families: associations with sexual risk-taking behavior. AIDS Behav. 1999;3(1):59-66.

29. Miller KS, Kotchick BA, Dorsey S, Forehand R, Ham AY. Family communication about sex: what are parents saying and are their adolescents listening? Fam Plan Perspect. 1998;30(5):218-22. \& 235.

30. Jaccard J, Dittus PJ, Gordon W. Maternal correlates of adolescent sexual and contraceptive behavior. Fam Plan Perspect. 1996;28(4):159-65. 185.

31. Rostosky SS, Regnerus MD, Wright MLC. Coital debut: the role of religiosity and sex attitudes in the Add Health Survey. J Sex Res. 2003;40(4):358-67.

32. Landis JR, Koch GG. The measurement of observer agreement for categorical data. Biometrics. 1977;33(1):159-74.

33. Newcomer SF, Udry JR. Parent-child communication and adolescent sexual behavior. Fam Plan Perspect. 1985;17(4):169-74.

34. Botchway AT. Parent and adolescent male communication about sexuality in the context of HIV/AIDS: a study in the Eastern region of Ghana. University of Bergen, Norway: MPhil Thesis; 2004

35. Poulsen MN, Miller KS, Lin C, Fasula A, Vandenhoudt H, Wyckoff SC, et al. Factors associated with parent-child communication about HIV/AIDS in the United States and Kenya: a cross-cultural comparison. AIDS Behav. 2010;14(5):1083-94.

36. Kiragu K, Obwaka E, Odallo D, Van Hulzen C. Communicating about sex: adolescents and parents in Kenya. AIDS STD Health Promotion Exch. 1996:3:11-3.

37. Opara PI, Eke GK, Akani NA. Mothers perception of sexuality education for children. Niger J Med. 2010;19(2):168-72.

38. Kunnuji MON. Parent-child communication on sexuality-related matters in the City of Lagos, Nigeria. Afr Dev. 2012:37(3):41-58.

39. Raffaelli M, Smart LA, van Horn SC, Hohbein AD, Kline JE, Chan W. Do mothers and teens disagree about Sexual communication? A mthodological reappraisal. J Youth Adolesc. 1999;28:395-402.

40. Lefkowitz ES. Beyond the yes-no question: measuring parent-adolescent communication about sex. New Dir Child Adolesc Dev. 2002;2002(97):43-56.

41. Teitelman AM, Ratcliffe SJ, Cederbaum JA. Parent-adolescent communication about sexual pressure, maternal norms about relationship power, and STI/HIV protective behaviors of minority urban girls. J Am Psychiatr Nurses Assoc 2008;14(1):50-60.

42. Dilorio CK, McCarty F, Pluhar E. Talking about HIV and AIDS: focus on parent-child discussions. In: Edgar TM, Noar SM, Freimuth VS, editors. Communication perspectives on HIV/AIDS for the 21st Century. New York: Taylor and Francis; 2009

43. Wyckoff SC, Miller KS, Forehand R, Bau JJ, Fasula A, Long N, et al. Patterns of sexuality communication between preadolescents and their mothers and fathers. J Child Fam Stud. 2008;17(5):649-62.

44. Dilorio C, Kelley M, Hockenberry-Eaton M. Communication about sexual issues: mothers, fathers, and friends. J Adolesc Health. 1999;24(3):181-9.

45. Stidham-Hall K, Moreau C, Trussell J. Patterns and correlates of parental and formal sexual and reproductive health communication for adolescent women in the United States, 2002-2008. J Adolesc Health. 2012;50(4):410-3.

46. Tesso D, Fantahun M, Enquselassie F. Parent-young people communication about sexual and reproductive health in E/Wollega zone, West Ethiopia: Implications for interventions. Reprod Health. 2012;9(1):13.

47. Kapungu $C T$, Baptiste D, Holmbeck G, McBride C, Robinson-Brown M, Sturdivant A, et al. Beyond the "birds and the bees": gender differences in sex-related communication among urban African-American adolescents. Fam Process. 2010;49(2):251-64

48. Sneed CD, Somoza CG, Jones T, Alfaro S. Topics discussed with mothers and fathers for parent-child sex communication among African-American adolescents. Sex Educ. 2013;13(4):450-8.

49. Aspy CB, Vesely SK, Oman RF, Rodine S, Marshall L, Fluhr F, et al. Youth-parent communication and youth sexual behavior: implications for physicians. Fam Med. 2006;38(7):500-4.

\section{Submit your next manuscript to BioMed Central and take full advantage of:}

- Convenient online submission

- Thorough peer review

- No space constraints or color figure charges

- Immediate publication on acceptance

- Inclusion in PubMed, CAS, Scopus and Google Scholar

- Research which is freely available for redistribution

Submit your manuscript at www.biomedcentral.com/submit 